\title{
Epidemiological characterization of respiratory tract infections caused by Mycoplasma pneumoniae during epidemic and post-epidemic periods in North China, from 2011 to 2016
}

\author{
Jiuxin $\mathrm{Qu}^{1,2^{*}}$ (D), Chunxia Yang ${ }^{2}$, Fang Bao ${ }^{3}$, Shuyan Chen ${ }^{4}, \mathrm{Li} \mathrm{Gu}^{2^{*}}$ and Bin $\mathrm{CaO}^{5}$
}

\begin{abstract}
Background: Mycoplasma pneumoniae (M. pneumoniae) is a commonly causative pathogen for respiratory tract infections (RTIs) in humans. The epidemiological features of M. pneumoniae infections during post-epidemic, including age distribution and the seasonality of the patients, are not well investigated.

Methods: We retrospectively analyzed the clinical data of 7835 consecutive RTIs patients (3852 adults and 3983 children) who visited a teaching hospital, and defined an epidemic (2011-2013) and a post-epidemic period (2014-2016). M. pneumoniae was detected by fluorescence-quantatitive PCR in respiratory samples. Informed consent was obtained by all adults and the legal representatives of patients aged $<18$ years, and the study was approved by Institutional Review Board of Beijing Chao-Yang Hospital (project approval number 10-KE-49).

Results: The median (IQR) age was 16 (53) years (range < 0-105 years). The M. pneumoniae positive rate was 14.4\% (21. $2 \%$, epidemic; $6.7 \%$, post-epidemic), with seasonal peaks from late summer to autumn during epidemic, and from fall to winter during post-epidemic period, which was highest in children aged 7-17 years. In epidemic, no statistical difference was found in the positive rates between children and adults among most months (except February, July and August), neither for the positive rates among age groups $(P=0.801)$. However, in post-epidemic period, significant differences were observed in the positive rates between children and adults in nearly every month $(P<0.05$ or $P<0.001$, except May), as well as in the positive rates among age groups $(P<0.001)$. Most of the older patient admissions and all of ICU admissions occurred during the epidemic.

Conclusions: Different patterns of age distribution and seasonality of M. pneumoniae RTIs between epidemic and post-epidemic periods were reported. Our results suggest that M. pneumoniae should be considered as a possible pathogen in pneumonia patients admitted to the ICU in the setting of an epidemic.
\end{abstract}

Keywords: Mycoplasma pneumoniae, Respiratory tract infection, Epidemic, Post-epidemic, Epidemiology

\footnotetext{
* Correspondence: qujiuxin@163.com; guli2013227@foxmail.com

'Department of Clinical Laboratory, The Third People's Hospital of Shenzhen,

Shenzhen, Guangdong, China

${ }^{2}$ Department of Infectious Diseases and Clinical Microbiology, Beijing

Chao-Yang Hospital, Beijing Institute of Respiratory Medicine, Capital Medical

University, Beijing, China

Full list of author information is available at the end of the article
}

(c) The Author(s). 2018 Open Access This article is distributed under the terms of the Creative Commons Attribution 4.0 International License (http://creativecommons.org/licenses/by/4.0/), which permits unrestricted use, distribution, and reproduction in any medium, provided you give appropriate credit to the original author(s) and the source, provide a link to the Creative Commons license, and indicate if changes were made. The Creative Commons Public Domain Dedication waiver (http://creativecommons.org/publicdomain/zero/1.0/) applies to the data made available in this article, unless otherwise stated. 


\section{Background}

Mycoplasma pneumoniae (M. pneumoniae) is a common pathogen of respiratory tract infections (RTIs) in humans, especially in children and young adults $[1,2]$. M. pneumoniae infections rangle clinically from mild, self-limiting upper respiratory symptoms to radiographically confirmed pneumonia requiring hospitalization and account for $10-30 \%$ of community-acquired pneumonia (CAP) cases [2-5]. Real-time polymerase chain reaction (PCR) has emerged as the primary techniques for detection of $M$. pneumoniae in surveillance programs and clinical practices in China [6,7], due to its increased sensitivity and specificity compared with culture-based and serological methods.

M. pneumoniae is the smallest self-living and cell wall-less bacterium. Droplet infection during close contact mediates transfer of this pathogen from person to person and can lead to an epidemic. Epidemics of $M$. pneumoniae infections are documented worldwide with durations of 3-5 years [8-10]. The fluctuations in the incidence of $M$. pneumoniae infections are considered due to a decline in a population's immunity and an increase of the immunologically naïve population [11], or changes in the proportion of individual strains with specific genotypes. Many investigations have focused on the epidemics, individual cases, and small clusters and outbreaks with various sizes [10, 12-14]; however, epidemiological features of M. pneumoniae infections during post-epidemic or non-epidemic periods, including age distribution, the seasonality and the hospitalization rate of the patients, have not been studied in detail.

In this study, we retrospectively analyzed patients of all age with M. pneumoniae RTIs from 2011 to 2016, covering an epidemic (2011-2013) and a post-epidemic period (2014-2016), and explored the epidemiological patterns of the infections during the two periods.

\section{Methods}

\section{Study population and samples}

During January 2011 to December 2016, 8213 consecutive patients with RTIs who visited Beijing Chao-Yang Hospital were prescribed by physicians with a PCR detection on $M$. pneumoniae. For the 378 patients who were re-diagnosed with the infection within two months of the initial diagnosis, only the data from the first incidence was analyzed in this study. We retrospectively analyzed the data of 7835 patients, including age, gender, date of visit, sample type and site of care. The M. pneumoniae RTIs included upper tract infection, bronchitis, bronchopneumonia, and pneumonia. The sample types included oropharyngeal swab, sputum, bronchoalveolar lavage fluid (Balf) and others (pleural effusion, cerebrospinal fluid and tissue).
Informed consent was obtained from all adults and the legal representatives of patients aged $<18$ years at admission for their clinical records to be used in future study. The study was approved by Institutional Review Board of Beijing Chao-Yang Hospital (project approval number 10-KE-49).

\section{Fluorescence quantitative PCR (FQ-PCR) testing of $M$. pneumoniae}

DNA was extracted from $200 \mu$ of clinical samples by manual nucleic acid extraction (Qiagen QIAmp DNA Mini Kit, Valencia, CA). As described by $\mathrm{Qu}$ et al. [7], M. pneumoniae was detected by a commercial FQ-PCR kit (Daan Gene, Guangzhou, China) approved by State Food and Drug Administration, targeting the $16 \mathrm{~S}$ ribosomal RNA gene [GenBank: AF132740]. The FQ-PCR mixture was prepared in a total volume of $45 \mu \mathrm{l}$, containing $3 \mu \mathrm{l}$ of sample DNA. FQ-PCR was performed under the following conditions: initial activation at $93{ }^{\circ} \mathrm{C}$ for $2 \mathrm{~min}$, followed by 10 cycles at $93{ }^{\circ} \mathrm{C}$ for $45 \mathrm{~s}$ and $55{ }^{\circ} \mathrm{C}$ for $1 \mathrm{~min}$, and 30 cycles at $93{ }^{\circ} \mathrm{C}$ for $30 \mathrm{~s}$ and $45^{\circ}$ $\mathrm{C}$ for $30 \mathrm{~s}$. The qualitative data from this procedure was used for the diagnosis. An internal control targeting human ribonuclease protein (hRNP) gene was incorporated. The amplifications were performed using the $A B$ 7500 Real Time PCR System (Applied Biosystems, Foster City, CA) according to the manufacturer's instructions.

\section{Statistical analyses}

Categorical variables were described with counts and percentages. Age was presented as median (IQR). The Wilcoxon rank sum test was used in comparison of age between groups and the $X^{2}$ or Fisher's exact test was used in comparisons of categorical variables. Statistical analyses were performed with SPSS Statistics (v21, IBM Corp., USA). $P$ value $<0.05$ was considered significant.

\section{Results}

Demographic characteristics of the patients

Overall, the median (IQR) age was 16 (53) years (range< $0-105 y e a r s$ ), and the children (aged < 18years) to adults (aged $\geq 18$ years) ratio was nearly 1:1 (3983:3852; Table 1 ). Oropharyngeal swab and sputum were the main samples, accounting for 66.3 and $29.2 \%$, respectively. The peak infection rates and number of $M$. pneumoniae positive cases were both noted at the age of 2 to 8 years (Additional file 1: Figure S1); Most of the patients who had M. pneumoniae infections (14.4\%, 1127/7835) were children $(19.7 \%$ vs. $8.9 \%, P<0.001)$ and female $(15.7 \%$ vs. $13.3 \%, P=0.003)$. Of the infected cases, $531 / 1127$ (47.1\%) and 582/1127 (51.6\%) patients with mild and mediate severity were treated as outpatients or in wards, only $14 / 1127(1.2 \%)$ patients were treated in Respiratory ICU (RICU) and Emergency ICU (EICU) or other ICUs. 
Table 1 Characteristic analysis on M. pneumoniae cases during 2011-2016. Data were represented as n (\%) in total cases, and as n (positivity, \%) in M. pneumoniae cases

\begin{tabular}{llll}
\hline Characteristic & Total & M. pneumoniae cases & $P$ value \\
\hline Age, median (IQR) & $16(53)$ & $11(19)$ & \\
Children & $3983(50.8)$ & $786(19.7)$ & $<0.001$ \\
Adults & $3852(49.2)$ & $341(8.9)$ & 0.003 \\
Gender & & & \\
Female & $3514(44.9)$ & $552(15.7)$ & \\
Male & $4321(55.1)$ & $575(13.3)$ & \\
Sample types & & & \\
Oropharyngeal swab & $5196(66.3)$ & $883(17.0)$ & \\
Sputum & $2290(29.2)$ & $225(9.8)$ & \\
Balf ${ }^{\text {a }}$ & $332(4.2)$ & $19(5.7)$ & \\
Others & $17(0.3)$ & $0(0)$ & \\
Site of care & & & \\
Outpatients & $3427(43.7)$ & $531(15.5)$ & \\
Wards & $3771(48.1)$ & $582(15.4)$ & \\
RICU and EICU & $357(4.6)$ & $11(3.1)$ & \\
Other ICUs & $280(3.6)$ & $3(1.1)$ & $1127(14.4)$ \\
Total & 7835 & & \\
\hline
\end{tabular}

${ }^{a}$ Balf: bronchoalveolar lavage fluid

$P$ value: statistical analyses were performed within $M$. pneumoniae cases

\section{Annual cases from 2011 to 2016}

Annual cases and the positive rate of $M$. pneumoniae during the study period are shown in Additional file 2: Figure. S2. The positive rate of $M$. pneumoniae during 2011 to 2013 was much higher than that during 2014 to 2016 (21.2\% vs. 6.7\%), on the basis of equal numbers of detected patients (3998 vs. 3837). To exclude the influence of seasonality on monthly distribution of $M$. pneumoniae cases, in this study, we defined an epidemic (during 2011 to 2013) and a post-epidemic period (during 2014 to 2016) by year.

\section{Monthly analyses on $M$. pneumoniae cases}

The monthly cases for the total study period are shown in Fig. 1. During the epidemic, there were three peaks with the positive rate of $M$. pneumoniae over $30 \%$, increased from late summer to autumn and lasted for 4 to 5 months. The lowest positive rate of $M$. pneumoniae was seen as $5 \%$ in March 2012. During the post-epidemic period, the largest number of $M$. pneumoniae cases was observed in autumn and winter, which coincided with the positive rate of M. pneumoniae. The positive rate of $M$. pneumoniae was lower than $2 \%$ in several single months, even no detections in May 2016. When both of the epidemic and post-epidemic merged into 12 months from January to December, the $M$. pneumoniae positivity values for every month during the epidemic was higher than those during the post-epidemic period (Fig. 2).

As shown in Additional file 3: Table S1, the M. pneumoniae positivity of children was significantly higher than that of adults almost in every month, except May and June. Both of the peaks of positive rate in children and adults were from July to November (Additional file 4: Figure. S3). When we analyzed the data divided by epidemic and post-epidemic, we found interesting epidemiological patterns of monthly $M$. pneumoniae positivity between children and adults (Additional file 5: Table S2 and Additional file 6: Figure S4). In epidemic, the $M$. pneumoniae positivity of children was significantly higher than that of adults only in February, July and August $(P=0.025, P<0.001$ and $P<0.001)$. The differences in $M$.

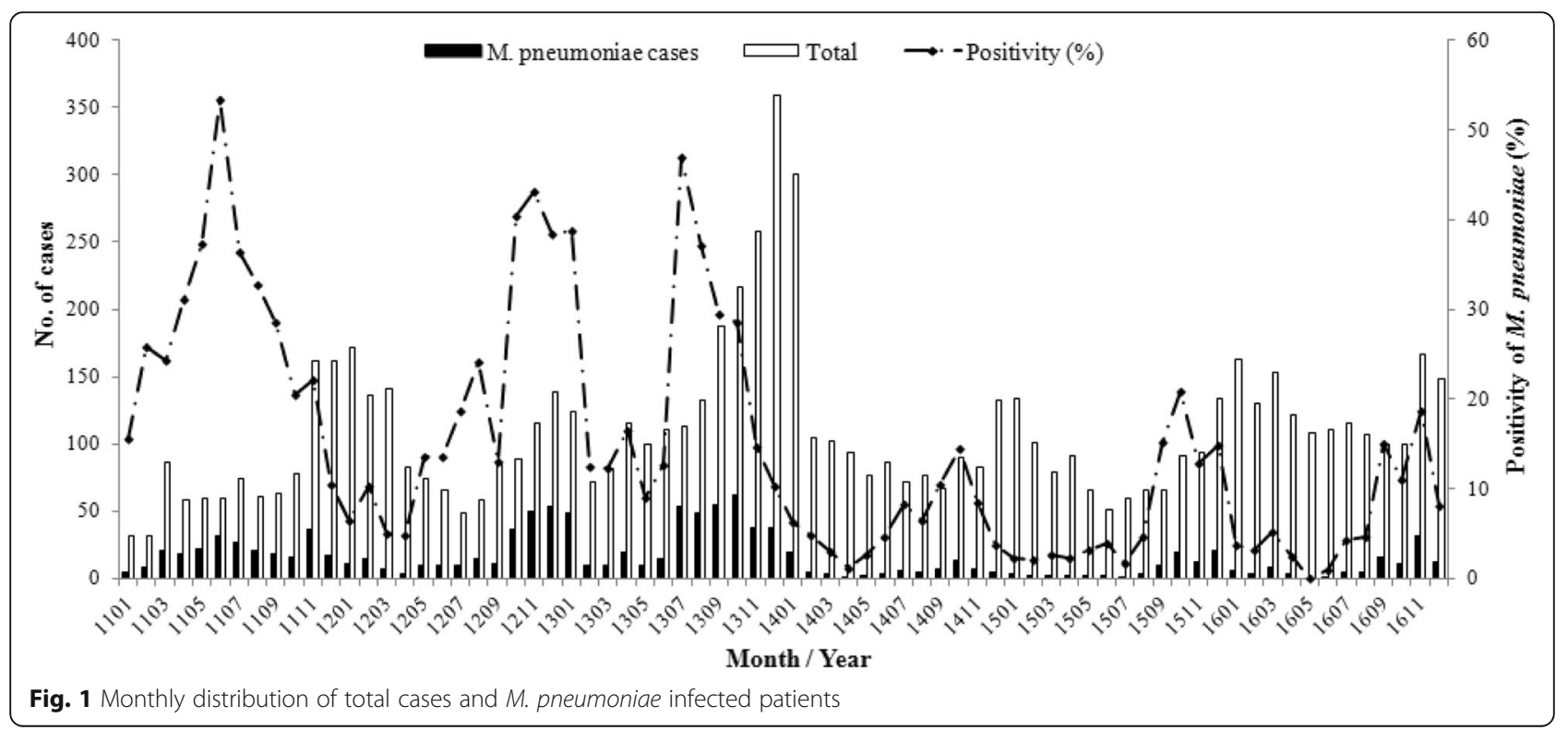




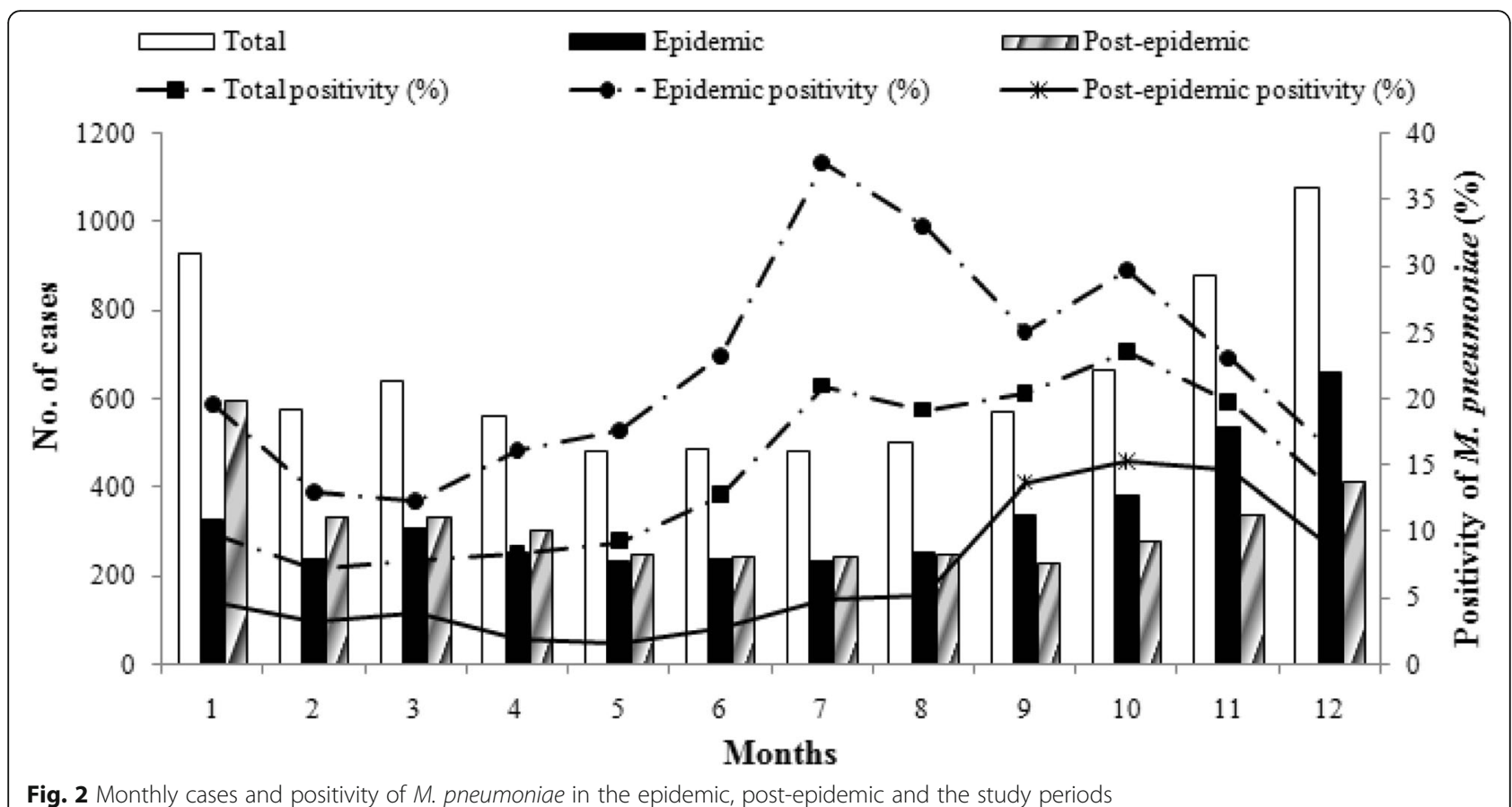

pneumoniae positivity were not statistically significant in most months, the positive rates of adults were even higher than that of children in June and December. Whereas during post-epidemic period, the M. pneumoniae positivity of children was significantly higher than that of adults in nearly every month, except May.

\section{Analyses on $M$. pneumoniae cases by age groups}

The patients were also divided into eight groups by age: 0-1 year (infants), 2-3 years (toddlers), 4-6 years (preschool children), 7-17 years (school children), 18-44 years (young adults), 45-64 years (older adults), 65-79 years (the elderly) and $\geq 80$ years (very elderly). As shown in Table 2 and Additional file 7: Figure S5, during the study period, the $M$. pneumoniae positivity increased from $8.2 \%$ of infants to the highest $32.9 \%$ of school children, then dropped steeply from $18.8 \%$ of young adults to 2.5 and $1.7 \%$ of elderly patients $(P<0.001)$. Similar trends of $M$. pneumoniae positivity were observed in epidemic and post-epidemic periods. However, the M. pneumoniae positivity among the age groups did not differ significantly $(P=0.801)$ in epidemic. Most of $M$. pneumoniae infected patients aged over 45 years occurred during epidemic.

\section{Analyses on positive sample type and site of care during} epidemic and post-epidemic

As shown in Table 3, the M. pneumoniae positivity of the main samples (swab, sputum and balf) was nearly

Table 2 Analysis of M. pneumoniae positivity among patients during epidemic and post-epidemic by age groups. Data were represented as $\mathrm{n}(\%)$ in total cases, and as $\mathrm{n}$ (positivity, \%) in M. pneumoniae cases

\begin{tabular}{|c|c|c|c|c|c|c|c|c|c|}
\hline \multirow[t]{2}{*}{ Age group } & \multirow[t]{2}{*}{ Total } & \multirow{2}{*}{$\begin{array}{l}\text { M. } \\
\text { pneumoniae } \\
\text { cases }\end{array}$} & \multirow[t]{2}{*}{$P$ value } & \multicolumn{2}{|c|}{ Epidemic } & \multirow{2}{*}{$\begin{array}{l}P \\
\text { value }\end{array}$} & \multicolumn{2}{|c|}{ Post-epidemic } & \multirow[t]{2}{*}{$P$ value } \\
\hline & & & & Total & M. pneumoniae cases & & Total & M. pneumoniae cases & \\
\hline Infants & 415 & $34(8.2)$ & $<0.001$ & 246 & $30(12.2)$ & 0.801 & 169 & $4(2.4)$ & $<0.001$ \\
\hline Toddlers & 1172 & $127(10.8)$ & & 768 & $113(14.7)$ & & 404 & $14(3.5)$ & \\
\hline Pre-school children & 1048 & $182(17.4)$ & & 671 & $136(20.3)$ & & 377 & $46(12.2)$ & \\
\hline School children & 1348 & $443(32.9)$ & & 849 & $325(38.3)$ & & 499 & $118(23.6)$ & \\
\hline Young adults & 1260 & $237(18.8)$ & & 677 & $182(26.9)$ & & 583 & $55(9.4)$ & \\
\hline Older adults & 1254 & $74(5.9)$ & & 432 & $59(13.7)$ & & 822 & $15(1.8)$ & \\
\hline The elderly & 928 & $23(2.5)$ & & 271 & $19(7.0)$ & & 657 & $4(0.6)$ & \\
\hline Very elderly & 410 & $7(1.7)$ & & 84 & $7(8.3)$ & & 326 & $0(0)$ & \\
\hline Total & 7835 & $1127(14.4)$ & & 3998 & $871(21.8)$ & & 3837 & $256(6.7)$ & \\
\hline
\end{tabular}

$P$ value: statistical analyses were performed on $M$. pneumoniae cases among age groups 
Table 3 Characteristic analysis on M. pneumoniae cases during epidemic and post-epidemic. Data were represented as n (\%) in total cases, and as n (positivity, \%) in M. pneumoniae cases

\begin{tabular}{|c|c|c|c|c|c|c|}
\hline \multirow[t]{2}{*}{ Characteristic } & \multicolumn{3}{|l|}{ Epidemic } & \multicolumn{3}{|c|}{ Post-epidemic } \\
\hline & Total & M. pneumoniae cases & $P$ value & Total & M. pneumoniae cases & $P$ value \\
\hline Age, median (IQR) & $9(30)$ & $11(20)$ & & $39(58)$ & $10(19)$ & \\
\hline Children & $2534(63.4)$ & $604(23.8)$ & $<0.001$ & $1449(37.8)$ & $182(12.6)$ & $<0.001$ \\
\hline Adults & $1464(36.6)$ & $267(18.2)$ & & $2388(62.2)$ & $74(3.1)$ & \\
\hline Gender & & & 0.145 & & & 0.102 \\
\hline Female & $1889(47.2)$ & $431(22.8)$ & & $1625(42.4)$ & $121(7.4)$ & \\
\hline Male & $2109(52.8)$ & $440(20.9)$ & & $2212(57.6)$ & $135(6.1)$ & \\
\hline Sample types & & & 0.39 & & & $<0.001$ \\
\hline Oropharyngeal swab & $3265(81.7)$ & 705 (21.6) & & $1931(50.3)$ & $178(9.2)$ & \\
\hline Sputum & $675(16.9)$ & $151(22.4)$ & & $1615(42.1)$ & $74(4.6)$ & \\
\hline Balf ${ }^{a}$ & $54(1.4)$ & $15(27.8)$ & & $278(7.2)$ & $4(1.4)$ & \\
\hline Others & $4(0.1)$ & $0(0)$ & & $13(0.4)$ & $0(0)$ & \\
\hline Site of care & & & 0.581 & & & $<0.001$ \\
\hline Outpatients & $2041(51.1)$ & $431(21.1)$ & & $1386(36.1)$ & $100(7.2)$ & \\
\hline Wards & $1807(45.2)$ & $426(23.6)$ & & $1964(51.2)$ & $156(7.9)$ & \\
\hline RICU and EICU & $96(2.4)$ & $11(11.5)$ & & $261(6.8)$ & $0(0)$ & \\
\hline Other ICUs & $54(1.4)$ & $3(5.6)$ & & $226(5.9)$ & $0(0)$ & \\
\hline
\end{tabular}

${ }^{a}$ Balf: bronchoalveolar lavage fluid

$P$ value: statistical analyses were performed within $M$. pneumoniae cases

equal (all over 20\%, $P=0.39$ ) during the epidemic, with the highest rate in balf (27.8\%). The M. pneumoniae positivity in post-epidemic was significantly different among the samples $(P<0.001)$, which decreased from upper $(9.2 \%)$ to lower tract samples (4.6 and $1.4 \%$ ). When analyzed the patients by site of care, the M. pneumoniae positivity between outpatients and inpatients was almost equal no matter in epidemic $(21.1 \%$ vs. $23.6 \%)$ or in post-epidemic (7.2\% vs. $7.9 \%)$. All M. pneumoniae cases that required treatment in ICUs occurred only during the epidemic.

\section{Discussion}

From 2011 to 2016, we observed that 14.4\% (1127/7835) of patients with RTIs were positive for M. pneumoniae, which was comparable with the global incidence as $12 \%$ (range 11-15\%) from the Atypical Pathogens Reference Laboratory Database [15]. Similar to previous reports $[16,17]$, the positive rates rose during the late summer and autumn and returned to low values during late winter and spring. The $M$. pneumoniae positive rates of children was significantly higher than those of adults $(19.7 \%$ vs. $8.9 \%, P<0.001)$ nearly in every month (Additional file 3: Table S1), and the highest rate was found in the school children group aged 7-17 years (32.9\%, 443/1348). Similarly, Kogoj et al. reported the proportion of M. pneumoniae RTIs were 19 and 7\% in children and adults, respectively, and the highest proportion was found in patients aged 6-16 years (26\%; 565/2162) [18]. These observations were consistent with the fact that the majority of outbreaks had occurred within a community or in closed or semi-closed settings such as military bases or schools. Moreover, compared with other publications on hospitalized patients $[17,19]$ and pediatric patients $[17,20-22]$, these results were more comprehensive to the patients with different severity and age because we reported on patients with $43.7 \%(3427 / 7835)$ as outpatients and adults to children ratio as 1:1 (3852:3983).

We firstly characterized the epidemiological features of $M$. pneumoniae infections during the epidemic and post-epidemic periods. Slightly different seasonality was displayed between the two periods: the positive rates peaked from late summer to autumn in epidemic period, and from fall to winter in the post-epidemic period. A positive correlation between increases in temperature and the occurrence of $M$. pneumoniae infections was reported by Onozuka and colleagues [23, 24], which might help explain the higher numbers that occur during warmer months.

The positive rate trends among age groups were similar between the two periods, with higher rates in patients aged 4-44 years old. The distribution corresponds to the findings from England and Wales [4, 25]. However, $M$. pneumoniae positive rate was significantly higher in preschool and school children during post-epidemic period $(P<0.001 ;$ Table 2$)$, and no statistical difference was 
found during epidemic period ( $P=0.801$; Table 2). Furthermore, most of older and elderly cases occurred during the epidemic period. A single genotype of $M$. pneumoniae is not the probable cause of the epidemic, since other studies have shown that both endemic and epidemic spreads of $M$. pneumoniae may be polyclonal $[11,26,27]$. Therefore, the potential reason for the observed pattern of age distribution during the two periods may be related to interactions between the pathogen and the immunological status of the human population [28]. A mathematical model of this process was recently reported [29]. During epidemics, due to the initial lack of protective immunity, $M$. pneumoniae infections can occur in humans of all age. Epidemics fade when the susceptible population gains protective immunity against the pathogen. However, younger individuals, who had not been exposed and thus did not gain protective immunity, were consequently infected during the post-epidemic time period. Further epidemiological investigations are warranted to yield more serological evidence for populations from different regions and periods and elucidate the biological and epidemiological reasons that contribute to this phenomenon.

Fulminant pneumonia accounted for $0.5-2 \%$ of all $M$. pneumoniae pneumonia cases and primarily affected young adults [30]. Two Chinese reports found that higher ICU admission rates (32.8\%) and fatal M. pneumoniae pneumonia were be found in younger children [21,31]. Moreover, in USA and Europe, the rates of ICU admission of hospitalized patients with $M$. pneumoniae pneumonia were reported as 10 and $16.3 \%[19,32]$. Here, during the whole period, only $14 / 1127$ (1.2\%) M. pneumoniae patients were treated in ICUs, with a median (IQR) age of 34 (37.75) years (range 15-83 years). Two factors may have contributed to the underreported number of ICU admissions: 1) nearly half of the detected patients were mildly symptomatic and treated as outpatients; 2) the severely ill children patients were immediately transferred to Children's Hospital. A special phenomenon was observed that all the ICU patients positive with $M$. pneumoniae were admitted during the epidemic period (Table 3), along with the significantly higher incidence of $M$. pneumoniae RTIs in elderly and very elderly patients (Table 2 ). Although Khoury et al. retrospectively investigated $M$. pneumoniae patients from 2007 to 2012, covering the epidemic 2010-2012, the yearly distribution of the M. pneumoniae cases were not described [32]; thus these results do not enable a comparison of ICU admission rates during the epidemic. Nevertheless, both previous and our results indicated that M. pneumoniae should be considered as a possible pathogen in pneumonia patients admitted to the ICU in the setting of epidemic.

Limited by the retrospective design of the study, multivariable analysis, and time trend analysis could not be performed since more medical data (e.g., history of drug use, recent hospitalization, socio-economical factors and etc) could not be obtained for most of the patients. No information collected to analyze the effect of sources of the patients on the results is another limitation, since parts of the studied patients came from cities out of Beijing. Considering the most reliable diagnosis for $M$. pneumoniae RTIs would come from a combination of two or more separate laboratory methods, such as serology and PCR [33-36], another limitation of the study is the lack of serological results. Due to the much lower sensitivity, serological testing is actually not widely performed in our hospital, especially for adults [7]. Moreover, although all analyzed patients presented with RTIs, we still could not exclude the possible carriages in the upper respiratory tract [37]. However, the results of studies on carriages are inconsistent, from a low rate $(<3 \%)$ [38] to a relatively high proportion (13.5 and 4.6\%) [39]. And the larger size and six-year consecutive detection strengthen our study.

\section{Conclusions}

Different patterns of age distribution and seasonality of M. pneumoniae RTIs between epidemic (2011-2013) and post-epidemic (2014-2016) periods were firstly reported. Most of older patients and all of ICU admissions infected with $M$. pneumoniae occurred in epidemic period.

\section{Additional files}

Additional file 1: Figure S1. Age distribution of total cases and $M$. pneumoniae infected patients. (DOCX $22 \mathrm{~kb}$ )

Additional file 2: Figure S2. Annual distribution of total cases and $M$. pneumoniae infected patients. (DOCX $24 \mathrm{~kb}$ )

Additional file 3: Table S1. Monthly analysis of $M$. pneumoniae infections in children and adults patients. Data were represented as $n(\%)$ in total cases, and as n (positivity, \%) in M. pneumoniae cases. (DOCX $15 \mathrm{~kb}$ )

Additional file 4: Figure S3. Cases distribution and M. pneumoniae positivity in children and adults patients grouped by months. (DOCX $48 \mathrm{~kb}$ )

Additional file 5: Table S2. Analysis of M. pneumoniae infections in children and adults during epidemic and post-epidemic. Data were represented as $\mathrm{n}(\%)$ in total cases, and as $\mathrm{n}$ (positivity, \%) in M. pneumoniae cases. (DOCX $16 \mathrm{~kb}$ )

Additional file 6: Figure S4. Cases distribution and M. pneumoniae positivity in children and adults patients during epidemic and postepidemic grouped by months. (DOCX $60 \mathrm{~kb}$ )

Additional file 7: Figure S5. Cases distribution and M. pneumoniae positivity in epidemic and post-epidemic among age groups. (DOCX 62 kb)

\section{Abbreviations}

Balf: bronchoalveolar lavage fluid; CAP: community-acquired pneumonia; EICU: Emergency ICU; FQ-PCR: the fluorescence quantitative PCR; hRNP: human ribonuclease protein; M. pneumoniae: Mycoplasma pneumoniae; RICU: Respiratory ICU; RTIs: respiratory tract infections 


\section{Acknowledgements}

We are grateful to Dr. Yi Mao, Yudong Yin, Zhenjia Liu, Hong Shen, Peng Wang and Ming Wei for their help with the collection of the specimens.

\section{Funding}

The design of the study, collection and analysis of data in this study was supported by the National Natural Science Foundation of China [grant numbers 81400005/H0104], Beijing Municipal Administration of Hospitals' Youth Programme [grant number 20150306], and the Beijing Science and Technology Project [grant numbers D101100049810002, Z131100002613001]. The interpretation of data and manuscript preparation in this study was supported by Shenzhen Key Laboratory of Biochip [ZDSYS201504301534057]. The publication fee was supported by Special Support Fund of Shenzhen for Introduced High-Level Medical Team, Translational medicine of Biochip in clinical laboratory [SZSM201412005].

\section{Availability of data and materials}

The datasets used and/or analysed during the current study are available from the corresponding author Jiu-Xin Qu on reasonable request.

\section{Authors' contributions}

$J Q$ and CY performed the PCR examination of the samples. JQ, FB, LG and BC interpreted the patient data. JQ and SC analyzed the data. JQ, SC and LG drawn the manuscript. All authors read and approved the final manuscript.

\section{Ethics approval and consent to participate}

All procedures performed in studies involving human participants were in accordance with the ethical standards of the Institutional Review Board of Beijing Chao-Yang Hospital (project approval number 10-KE-49) and with the 1964 Helsinki declaration and its later amendments or comparable ethical standards. Participant consent was written by the adults or the legal representatives of patients aged $<18$ years and informed consent forms were archived.

\section{Consent for publication}

Not applicable.

\section{Competing interests}

The authors declare that they have no competing interests.

\section{Publisher's Note}

Springer Nature remains neutral with regard to jurisdictional claims in published maps and institutional affiliations.

\section{Author details}

'Department of Clinical Laboratory, The Third People's Hospital of Shenzhen, Shenzhen, Guangdong, China. ${ }^{2}$ Department of Infectious Diseases and Clinical Microbiology, Beijing Chao-Yang Hospital, Beijing Institute of Respiratory Medicine, Capital Medical University, Beijing, China. ${ }^{3}$ Department of Pediatrics, Beijing Chao-Yang Hospital, Beijing Institute of Respiratory Medicine, Capital Medical University, Beijing, China. ${ }^{4}$ Department of Clinical Trial, The Third People's Hospital of Shenzhen, Shenzhen, Guangdong, China. ${ }^{5}$ Department of Respiratory and Critical Care Medicine, Clinical Microbiology and Infectious Disease Lab, China-Japan Friendship Hospital, Beijing, China.

\section{Received: 7 August 2017 Accepted: 11 July 2018}

\section{Published online: 17 July 2018}

\section{References}

1. Atkinson TP, Balish MF, Waites KB. Epidemiology, clinical manifestations, pathogenesis and laboratory detection of mycoplasma pneumoniae infections. FEMS Microbiol Rev. 2008;32(6):956-73.

2. Cao B, Zhao CJ, Yin YD, Zhao F, Song SF, Bai L, Zhang JZ, Liu YM, Zhang YY, Wang $\mathrm{H}$, et al. High prevalence of macrolide resistance in mycoplasma pneumoniae isolates from adult and adolescent patients with respiratory tract infection in China. Clin Infect Dis. 2010;51(2):189-94.

3. Waites KB, Bébéar CM, Robertson JA, Talkington DF, Kenny GE. Cumitech 34, Laboratory diagnosis of mycoplasmal infections. Coordinating ed, Nolte FS. Washington, DC: ASM Press; 2001

4. Chalker V, Stocki T, Litt D, Bermingham A, Watson J, Fleming D, Harrison T. Increased detection of mycoplasma pneumoniae infection in children in England and Wales, October 2011 to January 2012. Euro Surveill. 2012;17(6).
5. Eibach D, Casalegno JS, Escuret V, Billaud G, Mekki Y, Frobert E, Bouscambert-Duchamp M, Lina B, Morfin F. Increased detection of mycoplasma pneumoniae infection in children, Lyon, France, 2010 to 2011. Euro Surveill. 2012;17(8)

6. Pitcher D, Chalker VJ, Sheppard C, George RC, Harrison TG. Real-time detection of mycoplasma pneumoniae in respiratory samples with an internal processing control. J Med Microbiol. 2006;55(Pt 2):149-55.

7. Qu J, Gu L, Wu J, Dong J, Pu Z, Gao Y, Hu M, Zhang Y, Gao F, Cao B, et al. Accuracy of IgM antibody testing, FQ-PCR and culture in laboratory diagnosis of acute infection by mycoplasma pneumoniae in adults and adolescents with community-acquired pneumonia. BMC Infect Dis. 2013;13:172.

8. Lind K, Benzon MW, Jensen JS, Clyde WA Jr. A seroepidemiological study of mycoplasma pneumoniae infections in Denmark over the 50-year period 1946-1995. Eur J Epidemiol. 1997;13(5):581-6.

9. Lenglet A, Herrador Z, Magiorakos AP, Leitmeyer K, Coulombier D. European working group on mycoplasma pneumoniae s: surveillance status and recent data for mycoplasma pneumoniae infections in the European Union and European economic area, January 2012. Euro Surveill. 2012;17(5).

10. Nir-Paz R, Abutbul A, Moses AE, Block C, Hidalgo-Grass C. Ongoing epidemic of mycoplasma pneumoniae infection in Jerusalem, Israel, 2010 to 2012. Euro Surveill. 2012;17(8).

11. Chalker V, Stocki T, Mentasti M, Fleming D, Harrison T. Increased incidence of mycoplasma pneumoniae infection in England and Wales in 2010: multiocus variable number tandem repeat analysis typing and macrolide susceptibility. Euro Surveill. 2011;16(19).

12. Waller JL, Diaz MH, Petrone BL, Benitez AJ, Wolff BJ, Edison L, TobinD'Angelo M, Moore A, Martyn A, Dishman H, et al. Detection and characterization of mycoplasma pneumoniae during an outbreak of respiratory illness at a university. J Clin Microbiol. 2014;52(3):849-53.

13. Diaz MH, Benitez AJ, Winchell JM. Investigations of mycoplasma pneumoniae infections in the United States: trends in molecular typing and macrolide resistance from 2006 to 2013. J Clin Microbiol. 2015;53(1):124-30.

14. Chironna M, Loconsole D, De Robertis AL, Morea A, Scalini E, Quarto M, Tafuri S, Germinario C, Manzionna M. Clonal spread of a unique strain of macrolide-resistant mycoplasma pneumoniae within a single family in Italy. Medicine. 2016;95(11):e3160.

15. Arnold FW, Summersgill JT, Lajoie AS, Peyrani P, Marrie TJ, Rossi P, Blasi F, Fernandez P, File TM Jr, Rello J, et al. A worldwide perspective of atypical pathogens in community-acquired pneumonia. Am J Respir Crit Care Med. 2007;175(10):1086-93.

16. Feikin DR, Moroney JF, Talkington DF, Thacker WL, Code JE, Schwartz LA, Erdman DD, Butler JC, Cetron MS. An outbreak of acute respiratory disease caused by mycoplasma pneumoniae and adenovirus at a federal service training academy: new implications from an old scenario. Clin Infect Dis. 1999;29(6):1545-50

17. Kim EK, Youn YS, Rhim JW, Shin MS, Kang JH, Lee KY. Epidemiological comparison of three mycoplasma pneumoniae pneumonia epidemics in a single hospital over 10 years. Korean J Pediatr. 2015;58(5):172-7.

18. Kogoj R, Mrvic T, Praprotnik M, Kese D. Prevalence, genotyping and macrolide resistance of mycoplasma pneumoniae among isolates of patients with respiratory tract infections, Central Slovenia, 2006 to 2014 Euro Surveill. 2015;20(37).

19. Diaz MH, Benitez AJ, Cross KE, Hicks LA, Kutty P, Bramley AM, Chappell $J D$, Hymas W, Patel A, Qi C, et al. Molecular detection and characterization of mycoplasma pneumoniae among patients hospitalized with community-acquired pneumonia in the United States. Open Forum Infect Dis. 2015;2(3):ofv106.

20. Sun H, Xue G, Yan C, Li S, Zhao H, Feng Y, Wang L. Changes in molecular characteristics of mycoplasma pneumoniae in clinical specimens from children in Beijing between 2003 and 2015. PLoS One. 2017;12(1):e0170253.

21. Ma YJ, Wang SM, Cho YH, Shen CF, Liu CC, Chi H, Huang YC, Huang LM, Huang YC, Lin HC, et al. Clinical and epidemiological characteristics in children with community-acquired mycoplasma pneumonia in Taiwan: a nationwide surveillance. J Microbiol Immunol Infect = Wei mian yu gan ran za zhi. 2015;48(6):632-8.

22. Kawai Y, Miyashita N, Kubo M, Akaike H, Kato A, Nishizawa Y, Saito A, Kondo E, Teranishi H, Wakabayashi T, et al. Nationwide surveillance of macrolideresistant mycoplasma pneumoniae infection in pediatric patients. Antimicrob Agents Chemother. 2013;57(8):4046-9.

23. Onozuka D, Chaves LF. Climate variability and nonstationary dynamics of mycoplasma pneumoniae pneumonia in Japan. PLoS One. 2014;9(4):e95447. 
24. Onozuka D, Hashizume M, Hagihara A. Impact of weather factors on mycoplasma pneumoniae pneumonia. Thorax. 2009;64(6):507-11.

25. Brown RJ, Nguipdop-Djomo P, Zhao H, Stanford E, Spiller OB, Chalker VJ. Mycoplasma pneumoniae epidemiology in England and Wales: a National Perspective. Front Microbiol. 2016;7:157.

26. Pereyre S, Charron A, Hidalgo-Grass C, Touati A, Moses AE, Nir-Paz R, Bebear C. The spread of mycoplasma pneumoniae is polyclonal in both an endemic setting in France and in an epidemic setting in Israel. PLoS One. 2012; $7(6): e 38585$

27. Pereyre S, Touati A, Petitjean-Lecherbonnier J, Charron A, Vabret A, Bebear C. The increased incidence of mycoplasma pneumoniae in France in 2011 was polyclonal, mainly involving M. Pneumoniae type 1 strains. Clin Microbiol Infect. 2013;19(4):E212-7.

28. Barile MF, Grabowski MW, Kapatais-Zoumbois K, Brown B, Hu PC, Chandler DK. Protection of immunized and previously infected chimpanzees challenged with mycoplasma pneumoniae. Vaccine. 1994;12(8):707-14.

29. Omori R, Nakata Y, Tessmer HL, Suzuki S, Shibayama K. The determinant of periodicity in mycoplasma pneumoniae incidence: an insight from mathematical modelling. Sci Rep. 2015;5:14473.

30. Izumikawa K. Clinical features of severe or fatal mycoplasma pneumoniae pneumonia. Front Microbiol. 2016;7:800.

31. Ou ZY, Zhou R, Wang FH, Lu JP, Xia JQ, Xia HM, Zhang JT, Gong ST, Deng $\mathrm{L}, \mathrm{Wu} \mathrm{ZH}$, et al. Retrospective analysis of mycoplasma pneumoniae infection in pediatric fatal pneumonia in Guangzhou, South China. Clin Pediatr. 2008:47(8):791-6.

32. Khoury T, Sviri S, Rmeileh AA, Nubani A, Abutbul A, Hoss S, van Heerden PV, Bayya AE, Hidalgo-Grass C, Moses AE, et al. Increased rates of intensive care unit admission in patients with mycoplasma pneumoniae: a retrospective study. Clin Microbiol Infect. 2016;22(8):711-4.

33. Petitjean J, Vabret A, Gouarin S, Freymuth F. Evaluation of four commercial immunoglobulin G (lgG)- and IgM-specific enzyme immunoassays for diagnosis of mycoplasma pneumoniae infections. J Clin Microbiol. 2002;40(1):165-71.

34. Daxboeck F, Krause R, Wenisch C. Laboratory diagnosis of mycoplasma pneumoniae infection. Clin Microbiol Infect. 2003:9(4):263-73.

35. Martinez MA, Ruiz M, Zunino E, Luchsinger V, Avendano LF. Detection of mycoplasma pneumoniae in adult community-acquired pneumonia by PCR and serology. J Med Microbiol. 2008:57(Pt 12):1491-5.

36. Chaudhry R, Sharma S, Javed S, Passi K, Dey AB, Malhotra P. Molecular detection of mycoplasma pneumoniae by quantitative real-time PCR in patients with community acquired pneumonia. Indian J Med Res. 2013; 138:244-51

37. Foy HM. Infections caused by mycoplasma pneumoniae and possible carrier state in different populations of patients. Clin Infect Dis. 1993; 17(Suppl 1):S37-46.

38. Jain S, Williams DJ, Arnold SR, Ampofo K, Bramley AM, Reed C, Stockmann C, Anderson EJ, Grijalva CG, Self WH, et al. Community-acquired pneumonia requiring hospitalization among U.S. children. The New England journal of medicine. 2015;372(9):835-45.

39. Gnarpe J, Lundback A, Sundelof B, Gnarpe H. Prevalence of mycoplasma pneumoniae in subjectively healthy individuals. Scand J Infect Dis. 1992; 24(2):161-4

Ready to submit your research? Choose BMC and benefit from:

- fast, convenient online submission

- thorough peer review by experienced researchers in your field

- rapid publication on acceptance

- support for research data, including large and complex data types

- gold Open Access which fosters wider collaboration and increased citations

- maximum visibility for your research: over $100 \mathrm{M}$ website views per year

At BMC, research is always in progress.

Learn more biomedcentral.com/submissions 